\title{
Effect of occupational lead exposure on the family members of lead based industrial workers
}

\author{
Raviraja $A^{1}$, Vishal Babu G N ${ }^{2, *}$, Deepak K. S ${ }^{3}$, Thuppil Venkatesh ${ }^{4}$ \\ ${ }^{1}$ Assistant Professor, Dept. of Biochemistry, Karnataka Institute of Medical Sciences, Hubli, Karnataka, ${ }^{2}$ Associate Professor, \\ Dept. of Biochemistry, Government Medical College, Palakkad, Kerala, ${ }^{3}$ Statistician, Dept. of Community Medicine, \\ Government Medical College, Palakkad, Kerala, ${ }^{4}$ Director, NRCLPI, Dept. of Biochemistry, St. Johns Medical College, \\ Bangalore, Karnataka, India
}

*Corresponding Author:

Email: vishal2000babu@gmail.com

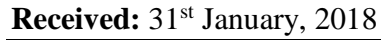

Accepted: $24^{\text {th }}$ April, 2018

\begin{abstract}
Introduction: A comparative study of family members of persons working in lead based industries and non-lead based industries were undertaken to evaluate the effect of lead on family members of lead based industrial workers and its effect on their liver function tests. As lead can be brought home though the shoes and dresses of lead based industrial workers, this study was done to evaluate the extent of lead exposure and its ill effects on liver functions on their family members as there were very few studies available to show the ill effects of lead on family members of lead based industrial workers.
\end{abstract}

Materials and Methods: Subjects were classified as.

Group-A: Controls- individuals who were working in non-lead based industries.

Group B: Adult Family members of individuals who were working in lead based industries.

Biomarkers of lead exposure estimated were BLL, $\delta$-ALAD, Hb and ZPP.

Liver function tests conducted were- estimation of serum enzymes like AST, ALT, ALP, GGT, serum bilirubin, serum total proteins and $\mathrm{A} / \mathrm{G}$ ratio.

Results: The study showed statistically significant increase in BLL $(p<0.001)$ and ZPP $(p<0.001)$ between the group A and group B. There was also statistically significant difference in two groups in ALP $(p<0.001)$. There was no significant difference in other liver function tests.

Conclusions: This study shows that lead brought home through the shoes and dresses of lead based industrial workers affects their family members. This could be prevented by taking simple precautionary measures such as changing clothes and taking shower before reaching home.

Keywords: Occupational lead, Family members, Liver function tests, Preventive measures.

\section{Introduction}

Lead is the number one environmental pollutant. ${ }^{1}$ Lead poisoning is an important environmental disease and is also a disease of life style that can have life-long adverse health effects. Lead is a toxic heavy metal, has no known biological functions in the human body and causes adverse health effects. For humans it is a cumulative poison and produces irreversible health effects once enters inside the body.

Today the major source of lead for adults is from occupation where lead and lead components are used, resulting in high prevalence of lead toxicity in the population exposed to such activity. Occupational exposure to lead remains a big problem in developing countries like India and occupational exposure is likely unregulated with little monitoring of the poisoning being done. ${ }^{2}$ Occupational exposure is usually seen in lead based industries such as - Lead acid battery industries, cable and wire products industries, soldering activities, motor vehicle assembly and in the glass, plastic, rubber, printing, ceramics, and paint industries. Occupational exposures can also result from secondary exposure for worker's families if workers bring home lead contaminated dust on their skin, clothes or shoes.
Occupational exposure leads to its slow accumulation in the body and it exerts different toxic effects depending on the level of its accumulation.

Lead can enter the body through ingestion, inhalation and dermal absorption. ${ }^{3}$ In adults with occupational exposure inhalation is the predominant form of absorption while for children gastrointestinal absorption is primary. Cutaneous absorption is essentially nonexistent for inorganic lead but exists for organic lead (tetraethyl lead used in gasoline) because of its lipid solubility. ${ }^{4}$

Lead toxicity can affect every organ system. It is a complex toxin and exerts numerous pathophysiologic effects in many organ systems. The most deleterious effects of lead are on erythropoiesis, kidney function and the central nervous system. Children's are more vulnerable to lead exposure than adults because a proportionately greater amount of lead they ingest is absorbed, more circulating lead enters their brain and their developing nervous system is more vulnerable. ${ }^{5}$

In developing countries like India most of the lead based workers are unaware of the toxic effects of lead and they work without taking proper precautionary measures in the workplace and carry the lead in their 
clothes, shoes and skin to their home, exposing their family members to lead.

Previous research provides a definite proof that exposure to lead causes significant adverse effects to multiple organ systems like nervous, haematological, renal and reproductive systems, ${ }^{6,7}$ but very few human studies have been conducted to know the effect of lead on liver functions. Lead can be stored in the liver after exposure and can cause adverse health effects. The role of liver in lead poisoning is very significant because of its importance in detoxification.

There are a very few studies which shows the significant changes in liver function in lead based industrial workers. Earlier studies on potential hepatotoxicity of lead in experimental animal systems used relatively high doses of inorganic lead salts. These studies reported alterations in hepatic xenobiotic metabolism, cholesterol metabolism, liver cell proliferation and DNA synthesis which is indicative of lead induced hepatic hyperplasia in experimental animals. ${ }^{8}$ In one of the studies done in Nigeria, Hepatotoxic effects of lead had been reported in occupationally lead exposed workers. ${ }^{6}$

There is no available data to know the ill-effects of lead on the family members of lead based industrial workers and on liver functions in Indian scenario.

\section{Aims}

Since liver is the major organs of storage, biotransformation and detoxification of lead we wanted to evaluate the toxic effects of this metal and its effects on liver functions even on the family members. The liver is composed of highly active metabolic tissue containing a huge complement of detoxification machinery referred to as phase I and phase II enzyme systems that ideally serve to guard other physiological systems from the toxic effects of xenobiotic compounds.

\section{Objectives}

1. To evaluate the BLL in family members of workers working in lead based industries.

2. To evaluate the LFT in family members of workers working in lead based industries.

3. To compare the BLL and LFT of family members of lead based industries with members working in non-lead based industries.

\section{Materials and Methods}

The study was carried out at the National Referral Centre for Lead Poisoning in India at St. John's Medical College Bangalore. Experiments were carried out by collecting blood samples from family members of lead based industrial workers and the results were compared with controls.

A comparative experiment study with 70 subjects in each group was carried out and the subjects studied were classified as
Group A: Controls-comprised of individuals who were working in non-lead based industries who are aged between 18 to 40 years.

Group B: Comprised of individuals who were family members of workers working in lead based industries (storage battery manufacturers) who are aged between 18 to 40 years.

Methods: The subjects were evaluated for

1. Estimation of blood lead by anodic stripping voltammetry using the ESA-3010B lead analyser. ${ }^{9,10}$

2. Estimation of hemoglobin in the whole blood by Drabkin's Method (1973). ${ }^{11,12}$

3. Estimation of erythrocyte $\delta$ aminolevulinic acid dehydratase ( $\delta$ ALAD) activity by the method of Berlin and Schaller. ${ }^{13}$

4. Estimation of zinc protoporphyrin in erythrocytes by using AVIV hematofluorometer. ${ }^{14}$

Other parameters were evaluated using fully automated analyser-ERBA-Excel 300.

\section{Results and Discussion}

Results of our findings are shown in Table 1 and 2.

In our study we observed a significant increase in BLL $(p<0.001)$ and ZPP $(p<0.001)$ in family members of lead based industrial workers compared to controls.

In our study age group toxic effects of lead were not noticed at this blood lead level but lead cumulatively accumulated and increased above the permissible limit $(10 \mu \mathrm{g} / \mathrm{dL})$ fixed by CDC (Centres for Disease Control) and the American Paediatric Association (APA) ${ }^{15}$ for infants, children (below 6 years), and women of childbearing age, though there is no safe blood lead level for normal population. This level is dangerous, especially to Foetus and young children as they are vulnerable to the neurologic effects of lead because their brains and nervous system are still developing and the blood brain barrier is incomplete. A study would be planned in children/infants of lead based industrial workers to find out the ill effects of lead exposure.

Among the liver function tests statistical significance was observed with respect to Alkaline phosphatase (ALP) $(\mathrm{p}<0.001)$ and other parameters were within normal limits in family members of lead based industrial workers. This is slightly different from one of the case reported in an adult battery worker, which showed mild elevation in liver enzyme ALT. ${ }^{16}$ According to centre for disease control and prevention the increase in BLL as a single parameter is more significant than any other parameters and in our study BLL was increased significantly. ${ }^{17}$ 
Table: 1 Comparison of biomarkers of lead exposures in categories

\begin{tabular}{|l|c|c|c|}
\hline Biomarkers of lead exposures & Group-A & Group-B & P value \\
\hline $\mathrm{BLL}(\mu \mathrm{g} / \mathrm{dl})$ & $5.29 \pm 3.05$ & $13.92 \pm 6.62$ & $<0.001$ \\
& $(0.7-13.3)$ & $(5.4-40.8)$ & \\
\hline $\mathrm{Hb}(\%)$ & $14.15 \pm 1.37$ & $13.29 \pm 1.12$ & 0.99 \\
& $(12.12-17.95)$ & $(10.2-16.47)$ & \\
\hline $\mathrm{ALAD}(\mu \mathrm{moles} / \mathrm{min} / \mathrm{L})$ & $51.50 \pm 7.11$ & $46.18 \pm 5.01$ & 0.035 \\
& $(32.8-64.4)$ & $(32.2-54.6)$ & \\
\hline $\mathrm{ZPP}(\mu \mathrm{g} / \mathrm{dl})$ & $23.22 \pm 6.71$ & $36.79 \pm 8.69$ & $<0.001$ \\
& $(10.0-38.0)$ & $(16.0-58.0)$ & \\
\hline
\end{tabular}

Results are presented as Mean \pm SD (Min-max)

Table 2: Comparison of liver function tests

\begin{tabular}{|l|c|c|c|}
\hline \multicolumn{1}{|c|}{ Liver function tests } & Group-A & Group-B & P value \\
\hline AST (IU/L) & $24.26 \pm 9.67$ & $25.25 \pm 14.49$ & 0.337 \\
& $(10.42-78.02)$ & $(6.8-65.9)$ & \\
\hline ALT (IU/L) & $23.21 \pm 10.39$ & $19.44 \pm 9.17$ & 0.98 \\
& $(6.94-64.0)$ & $(7.5-51.2)$ & \\
\hline ALP (K.A. Units) & $9.51 \pm 2.56$ & $12.08 \pm 2.98$ & $<0.001$ \\
& $(4.6-24.4)$ & $(5.2-22.4)$ & \\
\hline Gamma GT (U/L) & $19.75 \pm 8.66$ & $23.10 \pm 10.39$ & 0.032 \\
& $(4.0-47.0)$ & $(8.6-48.6)$ & \\
\hline Total Bilirubin (mg/dl) & $0.59 \pm 0.20$ & $0.71 \pm 0.28$ & 0.005 \\
& $(0.3-1.35)$ & $(0.4-1.59)$ & \\
\hline Direct Bilirubin (mg/dl) & $0.21 \pm 0.10$ & $0.24 \pm 0.12$ & 0.07 \\
& $(0.1-0.67)$ & $(0.1-0.69)$ & \\
\hline Indirect Bilirubin & $0.37 \pm 0.13$ & $0.47 \pm 0.21$ & 0.001 \\
(mg/dl) & $(0.1-0.85)$ & $(0.2-1.2)$ & \\
\hline Total protein (g/dl) & $7.44 \pm 0.52$ & $7.65 \pm 0.48$ & 0.01 \\
& $(6.23-8.78)$ & $(6.4-8.8)$ & \\
\hline Albumin (g/dl) & $4.13 \pm 0.40$ & $4.32 \pm 0.27$ & 0.0011 \\
& $(3.1-5.0)$ & $(3.7-5.04)$ & \\
\hline Globulin (g/dl) & $3.31 \pm 0.42$ & $3.33 \pm 0.42$ & 0.005 \\
& $(2.2-4.5)$ & $(2.08-4.05)$ & \\
\hline A/G ratio & $1.26 \pm 0.25$ & $1.32 \pm 0.21$ & 0.077 \\
& $(0.18-1.95)$ & $(1.03-2.06)$ & \\
\hline
\end{tabular}

\section{Conclusion}

The results show that the family members of lead based industrial workers are affected as BLL is significantly increased. This is due to lack of awareness in lead based industrial workers about the ill health effects of lead. They don't even know that the lead they carry home affects the health of their family members also. They should be educated properly about the importance of preventive measures to be taken in workplace and it should be strictly implemented in workplace by the employer. The employer also should provide all the preventive measures required to the workers in workplace.

Lead based industrial workers can prevent this secondary exposure to their family members by using simple preventive measures such as by changing their clothes and shoes used in workplace and by taking shower bath before returning home.
List of Abbreviations used:

$\delta$-ALAD-delta Amino levulinic acid dehydratase ALP-Alkaline Phosphatase

ALT-Alanine Transaminase

AST-Aspartate Transaminase

BLL-Blood Lead Level

GGT-Gamma Glutamyl Transferase

Hb-Hemoglobin

ZPP-Zinc Protoporphyrin

\section{References}

1. Herman DS, Geraldine M, Scott CC, Venkatesh T. Health hazards by lead exposure; Evaluation using ASV \& XRF. Toxico Ind Health - $2006 \mathrm{Jul} ; 22(6): 249-54$.

2. Imran Khan Mohammad, Abbas Ali Mahdi, Aryapu Raviraja, Islam Najmul, Ahmad Iqbal, Venkatesh Thuppil. Oxidative stress in painters exposed to low lead levels. Arh Hig Rada Toksikol. 2008;59(3):161-169. 
3. Raviraja. A, Vishal Babu.G.N, Bijoor AR, Geraldine.M, Venkatesh. T. Lead toxicity in a family as a result of occupational exposure. Arh Hig Rada Toksikol. 2008;59(2):127-133.

4. Staudinger KC, Roth VS. Occupational lead poisoning. American Family Physician. 1998 Feb. 15;57(4):1-14.

5. Ligsky TI, Schneider JS. Lead neurotoxicity in children: basic mechanisms and clinical correlates. Brain. 2003;126:5-19

6. Dioka CE, Orisakwe OE, Adeniyi FAA, Meludu SC. Liver and renal function tests in artisans occupationally exposed to lead in mechanic village in Nnewi, Nigeria. Int J Environ Res Public Health. 2004;1(1):21-25.

7. Gidlow DA. Lead toxicity in depth review. Occup Med. 2004;54(2):76-81.

8. US, EPA. Air quality criteria document for lead $(\mathrm{Pb})$, Washington DC: US Environmental Protection Agency. 1986;4:264-7.

9. Jagner D, Graneli A. Potentiometric stripping analysis. Anal Chim Acta. 1976;83:19-26.

10. Kisner HJ. "Talking about Technology", ESA model 3010 B Lead Analyzer, Clinical laboratory Management review. New Hampshire.1993.

11. Drabkins DL, Austin JM. Spectrophotometric constants for common Hemoglobin derivatives in Human, dog \& rabbit blood. J Biol Chem. 98:719-723(1932).

12. Carl AB, Edward RA. Tietz textbook of clinical chemistry. $3^{\text {rd }}$ ed. W. B. Saunders Company, Philadelphia 1999, p. 1067.
13. Berlin A, Schaller K.H. European standardized method for the determination of $\delta$-aminolevulinic acid dehydratase activity. Klin. Chem. Klin. Biochem. 1974:12:389-390.

14. Blumberg WE, Elsinger J, Lamola AA, Zuckerman DM. Zinc protoporphyrin level in blood determined by a portable Hematoflourometer. A screening device for lead poisoning. J Lab Clin Med. 1977;89(4):712-73.

15. Agency for Toxic Substances and Disease Registry (ATSDR). Toxicological profile for Lead. Atlanta, GA: US Department of Health and Human Services, Public Health Service. Public health service;2005:63.

16. Geraldine M, Herman SD, Venkatesh. T. Chronic Lead Poisoning in an adult battery worker-a case report. Occupational Medicine. 2003;53(7):476-478.

17. Dr. Vishal Babu G N, Dr. Raviraja A, Dr. Thuppil Venkatesh. Magnitude of lead poisoning among unorganized battery workers. International Journal of Biological and Medical Research 2014;5(2):4129-4132.

How to cite this article: Raviraja $\mathrm{A}$, Vishal Babu GN, Deepak KS, Venkatesh T. Effect of occupational lead exposure on the family members of lead based industrial workers. Int J Clin Biochem Res. 2018;5(3):411-414. 